\title{
PENINGKATAN PEMAHAMAN MATERI KUANTISASI BESARAN FISIS PADA CALON GURU FISIKA MENGGUNAKAN METODE DISKUSI KELAS DAN SCAFFOLDING
}

\author{
Utama Alan Deta \\ Jurusan Fisika, Fakultas Matematika dan Ilmu Pengetahuan Alam, Universitas Negeri Surabaya \\ Jl. Ketintang, Gd C3 Lt 1, Surabaya 60231, Indonesia \\ e-mail: utamadeta@unesa.ac.id
}

Diterima: 21 Juni 2017. Disetujui: 7 Oktober 2017. Dipublikasikan: 28 Oktober 2017

\begin{abstract}
Abstrak: Kuantisasi besaran fisis merupakan materi penting dalam Fisika kuantum. Topiknya merupakan jembatan dan titik awal revolusi pemikiran Fisis dikenalnya Fisika Kuantum. Penelitian ini bertujuan untuk mengetahui penerapan metode diskusi untuk meningkatkan hasil belajar mahasiswa pendidikan fisika pada materi kuantisasi besaran fisis. Penelitian ini dilakukan di Jurusan Fisika Universitas Negeri Surabaya pada matakuliah Fisika Kuantum khususnya materi Kuantisasi Besaran Fisis. Penelitian ini merupakan Penelitian Tindakan Kelas dengan obyek penelitian mahasiswa Pendidikan Fisika B 2012 dan/atau mahasiswa yang memprogam matakuliah Fisika Kuantum pada tahun ajaran 2014/2015. Penelitian dilakukan dengan 2 siklus. Pada siklus pertama, hasil belajar mahasiswa sebesar 63,6\%. Siklus dilanjutkan hingga hasil belajar mahasiswa lebih dari $75 \%$ yakni pada siklus kedua sebesar $79,4 \%$. Perbedaan utama dari siklus 1 dan siklus 2 adalah adanya scaffolding oleh dosen di siklus kedua. Scaffolding yang diberikan berupa pertanyaan-pertanyaan bantuan agar mahasiswa mampu menjelaskan konsep materi yang diajarkan dan proses diskusi dapat berjalan dengan lebih baik.
\end{abstract}

Kata kunci: diskusi kelas, kuantisasi besaran fisis, hasil belajar mahasiswa, scaffolding

\section{THE IMPROVEMENT OF QUANTIFICATION OF PHYSICAL SIZE UNDERSTANDING OF THE PRE-SERVICE PHYSICS TEACHERS USING CLASS DISCUSSION METHODS AND SCAFFOLDING}

\begin{abstract}
Physical quantities quantization is an essential subject in Quantum Physics. The topic used as a bridge and a starting point of the revolution of physical thinking into the real Quantum Physics. This study aims to determine the application of discussion methods to enhance the learning outcomes of physics education students on the topic of quantization of physical quantities. This research conducted at the Physics Department, Universitas Negeri Surabaya on the subject of Quantum Physics. This research is a Classroom Action Research with research object is students of Physics Education B 2012 and students who programmed Quantum Physics course in academic year 2014/2015. The study conducted with two cycles. In the first cycle, the learning outcomes are 63.6\%. The cycle is continued until the learning outcomes more than 75\%, that is, in the second cycle is 79.4\%. The main difference between cycle 1 and cycle 2 is the presence of scaffolding by lecturers in the second cycle. Scaffolding was given in the form of helping questions so that the students can explain the concept of the material being taught and the discussion process can run better.
\end{abstract}

C 2017 Pendidikan Fisika, FTK UIN Raden Intan Lampung

Keywords: class discussion, physical quantities quantization, students' learning outcomes, scaffolding

\section{PENDAHULUAN}

Mekanika kuantum adalah cabang fisika yang menjelaskan perilaku materi serta interaksinya dengan energi pada skala atomik dan partikel subatomik.
Mekanika kuantum saat ini dianggap cabang fisika yang paling aplikatif dalam menunjang ilmu pengetahuan dan teknologi. 
Berdasarkan data SIAKAD Unesa, prosentasi ketidaklulusan mahasiswa 2011 kelas A dalam mata kuliah fisika kuantum sebesar 29\%. Adapun prosentase mahasiswa yang mendapatkan nilai "C" sebesar $42 \%$. Rendahnya nilai matakuliah ini dikarenakan kurangnya minat mahasiswa dalam pembelajaran. Hal ini disebabkan oleh pembelajaran matakuliah ini hanya diberikan dengan metode ceramah. Dengan demikian, pembelajaran menjadi terasa membosankan. Hal ini serupa dengan penelitian Yuliani yaitu dalam mempelajari mekanika kuantum dibutuhkan media pembelajaran yang dapat menggambarkan sifat abstrak dari mekanika kuantum (Yuliani, 2017). Selain dengan media pembelajaran, sifat abstrak dari mekanika kuantum dapat dibantu dengan pendekatan pembelajaran (Saregar, 2016)

Berdasarkan hasil wawancara kepada beberapa mahasiswa Fisika, materi yang membosankan jika diajarkan menggunakan metode ceramah adalah Kuantisasi Besaran Fisis. Materi Kuantisasi Besaran Fisis merupakan titik jenuh dari Fisika Klasik dalam menjelaskan fenomena-fenomena kuantum. Pada dasarnya, materi ini merupakan kilas balik materi pada mata kuliah Fisika Modern sehingga mahasiswa merasa bosan jika materi tersebut disampaikan dengan metode ceramah. Hal ini sesuai dengan penelitian Rohaniawati bahwa metode ceramah akan membosankan dan menjenuhkan terlebih dilakukan disetiap pertemuan pembelajaran (Rohaniawati, 2016). Tenaga pendidik juga dapat menggabungkan beberapa metode yang sesuai dengan keadaan kelas (Wekke \& Astuti, 2017)

Untuk menumbuhkan minat mahasiswa pada matakuliah Fisika Kuantum, diperlukan metode pembelajaran yang sangat melibatkan mahasiswa dalam pembelajaran. Mahasiswa dituntut lebih aktif dan berpikir tingkat tinggi untuk memecahkan permasalahan-permasalahan dalam fisika kuantum. Dengan melibatkan mahasiswa dalam pembelajaran, diharapkan mahasiswa lebih tertarik ketika mempelajari Fisika Kuantum. Hal ini seperti yang diungkapkan oleh (U. A. Deta, -, \& Widha, 2013).

Secara hakekat, belajar merupakan proses perubahan dari tingkah laku seperti yang diharapkan. belajar adalah proses usaha yang dilakukan oleh seseorang agar memperoleh suatu perubahan tingkah laku baru secara keseluruhan, sebagai hasil pengalaman pribadi dalam melakukan interaksi dengan lingkungan. Belajar memerlukan partisipasi aktif peserta didik pada proses pembelajaran (U. A. Deta et al., 2013). Salah satu metode pembelajaran yang melibatkan mahasiswa secara aktif adalah metode diskusi.

Diskusi merupakan strategi atau prosedur dalam mengajar (Dwikoranto, 2011). Diskusibukan merupakan model pengajaran susungguhnya. Pada metode Diskusi, peserta didik dihadapkan pada suatu permasalahan yang dapatberbentuk pernyataan maupun pertanyaan problematis untuk dibahas, diselesaikan, dan dipecahkan bersama. Dalam diskusi, antara pengajar dengan peserta didik atau peserta didik dengan peserta didik lain saling bertukar gagasan atau pendapat. Diskusi dilakukan oleh pengajar untuk mencapai sedikitnya tiga tujuan pembelajaran khusus yang penting, antara lain meningkatkan cara berfikir peserta didik dan membantu mereka membangun sendiri pemahaman materi; menumbuhkan keterlibatan dan keikutsertaan peserta didik; membantu peserta didik untuk mempelajari keterampilan komunikasi dan proses berfikir.

(Utama Alan Deta \& Suprapto, 2012) menyatakan bahwa hasil belajar dari siswa yang diberikan metode diskusi lebih tinggi jika dibandingkan dengan hasil belajar siswa yang diberikan 
pembelajaran klasikal. Hal senada diungkapkan oleh (Nadeak, Margiati, \& Halidjah, 2013). Nadeak menyatakan bahwa dengan menggunakan metode diskusi terjadi peningkatan aktivitas belajar siswa. Adapun aktivitas belajar siswa yang meningkat meliputi aktivitas fisik, mental, maupun emosional. Dalam menerapkan metode diskusi, diperlukan teknik Scaffolding agar proses diskusi berjalan dengan baik.

Scaffolding adalah istilah yang dicetuskan oleh Jerome Bruner (Applebee, 1983). Scaffolding merupakan proses yang digunakan orang yang lebih dewasa untuk menuntun anak-anak melalui zona perkembangan proksimal mereka. Teori Vygotsky merupakan landasan dari metode Scaffolding. Menurut Vygotsky dalam (Trianto, 2007) pembelajaran dapat terjadi ketika anak bekerja atau belajar menangani sendiri tugas-tugas yang belum pernah dipelajari. Tugas-tugas tersebut harus berada dalam Zone of Proximal Development (ZPD) yakni sedikit di atas perkembangan anak saat ini. Vygotsky meyakini bahwa fungsi mental yang lebih tinggi secara umum dapat timbul dalam kerjasama dan diskusi antar individu.

(Anghileri, 2006) membagi metode scaffolding menjadi tiga level, yakni: level pertama berkaitan dengan environmental provisions; level kedua berkaitan dengan explaining, reviewing, dan restructuring; serta level ketiga berkaitan dengan developing conceptual thinking. Pada level pertama, scaffolding dapat diberikan dengan cara melakukan pengkondisian lingkungan belajar yang mendukung kegiatan belajar siswa. Level selanjutnya dilakukan dengan memberikan penjelasan, melakukan review, dan melakukan restrukturisasi secukupnya terkait dengan materi yang disampaikan. Pada level akhir, proses ini diarahkan untuk dapat mengembangkan pola berpikir konseptual siswa.
Pemberian scaffolding dapat menjadi tumpuan, baik berupa tumpuan konseptual maupun tumpuan metakognitif. (Ding, Reay, Lee, \& Bao, 2011) menunjukkan tingkat pemahaman siswa jauh lebih baik ketika diberikan melalui scaffolding dibandingkan dengan pemberian langsung konsep fisis oleh guru (direct cuing) dalam permasalahan yang disajikan. Di sisi lain, terkadang siswa secara langsung diminta untuk menyelesaikan permasalahan fisika yang disajikan tanpa melalui suatu proses konstruksi konsep dasar sehingga siswa mudah mengalami kebingungan dan siswa hanya menghafalkan rumus fisika secara matematis.

Beberapa peneliti lain telah mengkaji penerapan Scaffolding dalam metode pembelajaran tertentu. Rahmatiah telah mengkaji tentang pengaruh Scaffolding dalam pembelajaran Group Investigation terhadap hasil pembelajaran. Kelompok siswa yang belajar dengan menggunakan strategi scaffolding konseptual dalam pembelajaran Group Investigation mencapai prestasi belajar yang lebih tinggi dibandingkan kelompoksiswa yang belajar tanpa menggunakan Scaffolding (Rahmatiah, H, \& Kusairi, 2016). Hasil yang senada juga diperoleh oleh Haniin (Haniin, Diantoro, \& H, 2015) mengkaji penerapan Scaffolding pada metode pembelajaran TPS (Think Pair Share).

Meskipun telah banyak penelitian tentang penerapan Scaffolding dalam pembelajaran Fisika, penelitian tentang Scaffolding pada metode diskusi masih jarang dibahas oleh peneliti lain. Penelitian ini akan menelaah proses diskusi dan scaffolding mahasiswa ketika mempelajari materi kuantisasi besaran fisis di mata kuliah Fisika Kuantum. Proses diskusi didampingi dengan scaffolding agar mahasiswa dapat mengkonstruk materi dengan baik. Dengan pelibatan mahasiswa secara aktif dengan diskusi dan pemberian materi secara scaffolding, diharapkan mahasiswa 
mampu memahami materi efek Foto listrik dan efek Compton dengan baik

\section{METODE PENELITIAN}

Penelitian ini merupakan Penelitan Tindakan Kelas (PTK) yang bertujuan untuk meningkatkan kualitas proses belajar mengajar di kelas. Penelitian tindakan merupakan suatu penelitian yang dilaksanakan oleh suatu pendidik untuk meningkatkan kualitas pengajaran serta mengatasi berbagai permasalahan dalam pembelajaran. Penelitian ini terdiri dari beberapa siklus. Pada masing-masing siklus terdiri dari perencanaan, pelaksanaan pengamatan, refleksi yang menghasilkan revisi-revisi yang diterapkan pada putaran berikutnya putaran terakhir hingga tujuan tercapai. Setelah mahasiswa memahami minimal $75 \%$ materi yang diajarkan, siklus dihentikan.

Penelitian ini dilaksanakan di Jurusan Fisika FMIPA Unesa pada awal semester 5 hingga pertengahan semester pada tahun akademik 2014/2015. Adapun subyek penelitian ini adalah mahasiswa Pendidikan Fisika B 2012 semester 5. Terdapat 2 jenis data yang didapatkan dari penelitian ini, yakni data primer dan data sekunder. Data primer diperoleh dari hasil belajar mahasiswa setiap akhir siklus sedangkan data sekunder diperoleh dari hasil refleksi siklus, wawancara, dan angket respon mahasiswa.

Instrumen pembelajaran yang digunakan dalam penelitian ini adalah Rencana Pembelajaran Semester (RPS), Satuan Acaran Perkuliahan (SAP), dan Lembar Kerja Mahasiswa (LKM). RPS merupakan perencanaan proses pembelajaran yang disusun untuk setiap matakuliah. Rincian dari proses pembelajaran tersebut tertuang dalam SAP. LKM digunakan untuk menuntun mahasiswa dalam melakukan diskusi kelas.

Instrumen penelitian yang digunakan untuk memperoleh data dalam penelitian ini adalah tes hasil belajar dan angket respon mahasiswa. Tes hasil belajar mahasiswa digunakan untuk mengukur kemampuan siswa sesudah pelaksanaan pembelajaran pada materi Kuantisasi Besaran Fisis. Sedangkan angket respons mahasiswa digunakan untuk mengetahui hasil respons siswa terhadap proses pembelajaran.

\section{HASIL DAN PEMBAHASAN Hasil Penelitian}

Pada siklus pertama, kegiatan diskusi kelas dilaksanakan secara bebas, tanpa arahan dari dosen. Mahasiswa diminta untuk mendiskusikan materi Radiasi Benda Hitam. Siswa diberikan LKS yang berisi topik utama dan pertanyaanpertanyaan terkait konsep Radiasi benda Hitam. Setelah berdiskusi secara kelompok, mahasiswa diminta menyampaikan hasil diskusinya di depan kelas. Di akhir pembelajaran, dosen akan memberikan penjelasan yang masih belum tersampaikan dalam diskusi kelas. Dengan demikian, materi yang diajarkan tetap utuh tersampaikan dalam kegiatan belajar mengajar.

Setelah peneliti melaksanakan proses belajar mengajar, peneliti melakukan tes hasil belajar untuk mengetahui pemahaman konsep mahasiswa pada materi Radiasi Benda Hitam. Berdasarkan hasil analisis, diperoleh rata-rata hasil belajar dari mahasiswa sebesar 63,56 . Hal ini masih lebih rendah dari kriteria kelulusan minimum yang ditetapkan yakni $75 \%$. Dengan demikian, penelitian harus dilanjutkan ke siklus berikutnya.

Sebelum peneliti melanjutkan ke siklus berikutnya, peneliti dan pengamat melakukan refleksi hasil pembelajaran pada siklus pertama. Berdasarkan hasil refleksi, dapat diketahui bahwa mahasiswa sering mengalami kesulitan untuk memahami konsep baik secara mandiri maupun kelompok. Hal ini lebih dikarenakan pada proses diskusi di siklus pertama, mahasiswa dibebaskan secara 
penuh untuk melakukan diskusi dan tanya-jawab tanpa arahan dari dosen.

Pada siklus kedua, kegiatan diskusi kelas dilaksanakan dengan arahan dari dosen. Mahasiswa diminta untuk mendiskusikan materi Kuantisasi Besaran Fisis. Perbedaan utama antara siklus pertama dan siklus kedua adanya proses Scaffolding. Pada siklus ini, dosen ikut membimbing mahasiswa dalam diskusi kelompok. Bimbingan dilakukan dengan adanya pertanyaan-pertanyaan bantuan (scaffolding) yang diberikan oleh dosen untuk membantu permasalahan utama dalam diskusi. Pemberian pertanyaan ini tidak dilakukan terus menerus. Seiring dengan terjadinya peningkatan kemampuan mahasiswa, secara berangsur-angsur dosen mengurangi dan melepaskan mahasiswa untuk belajar secara mandiri.

Setelah peneliti melakukan proses belajar mengajar, peneliti memberikan tes hasil belajar pada materi Efek Fotolistrik. Berdasarkan hasil analisis, diperoleh ratarata hasil belajar dari mahasiswa sebesar 79,44. Hal ini sudah di atas kriteria kelulusan minimum yang ditetapkan yakni $75 \%$. Selain itu, $84,44 \%$ nilai mahasiswa meningkat jika dibandingkan dengan nilai pada siklus pertama (tampak seperti pada Gambar1). Dengan demikian, penelitian dihentikan hingga siklus kedua.

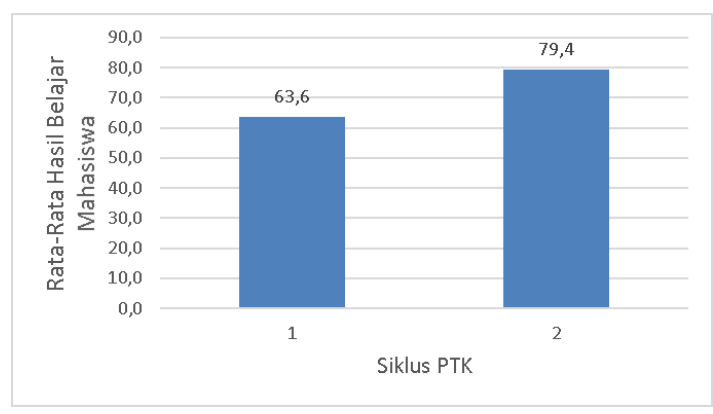

Gambar 1. Rata-Rata Hasil Belajar Mahasiswa Tiap Siklus

\section{Pembahasan}

Diskusi merupakan situasi dimana siswa-siswa dihadapkan kepada suatu masalah yang bisa berupa pernyataan atau pertanyaan yang bersifat problematis untuk dibahas dan dipecahkan bersama sehingga antara dosen dengan mahasiswa atau mahasiswa dengan mahasiswa yang lain bertukar gagasan dan pendapat satu sama lain. Dengan penerapan metode diskusi, siswa mengkonstruk pengetahuannya baik secara mandiri maupun kelompok. Selain itu siswa lebih antusias dalam melaksanakan pembelajaran.

Berdasarkan hasil angket, respons siswa terhadap metode diskusi cukup baik. $80 \%$ mahasiswa berpendapat bahwa metode diskusi sangat menarik dan tidak membosankan. Hal ini disebabkan mahasiswa aktif dalam pembelajaran. Hal ini dipertegas dengan hasil angket yakni $82,22 \%$ mahasiswa menyatakan bahwa metode ini membuat mahasiswa aktif dalam proses belajar mengajar. Mahasiswa menggali sendiri materi yang dipelajari dalam perkuliahan sehingga mahasiswa tidak hanya mendengarkan ceramah dari dosen. Hal ini berakibat pada $77,78 \%$ mahasiswa termotivasi dalam proses belajar mengajar.

Materi-materi dalam fisika kuantum bersifat abstrak dan perlu keterampilan matematis yang cukup tinggi agar mahasiswa mudah mempelajarinya. Hal ini senada dengan pernyataan mahasiswa yakni hanya sekitar $60,00 \%$ mahasiswa saja yang setuju bahwa dengan penerapan metode diskusi mempermudah mahasiswa dalam memahami materi fisika kuantum, khususnya pada topic kuantisasi besaran fisis. Namun, metode ini cukup baik untuk meningkatkan motivasi dan keaktifan mahasiswa dalam proses belajar mengajar.

Pembelajaran fiska dengan metode diskusi dapat meningkatkan hasil belajar. Hal ini senada dengan(Utama Alan Deta \& Suprapto, 2012)yang menyatakan bahwa rata-rata hasil belajar siswa yang diajar dengan metode diskusi lebih tinggi jika dibandingkan dengan pembelajaran 
biasa. Dengan metode diskusi, mahasiswa lebih aktif dalam mengeksplorasi dan mengkomunikasikan materi kuliah sehingga dapat meningkatkan pemahaman mahasiswa terhadap materi yang dibahas.

Pada siklus pertama, mahasiswa cukup antusias dalam kegiatan pembelajaran. Mahasiswa berdiskusi secara lepas di dalam kelas. Namun, terjadi permasalahan ketika mahasiswa tidak dapat menjawab suatu persoalan. Permasalahan ini berdampak pada rata-rata hasil belajar mahasiswa yang masih di bawah $75 \%$ seperti pada Gambar 1.

Siklus kedua dimulai dengan menambahkan proses scaffolding berupa pemberian pertanyaan-pertanyaan bantuan kepada mahasiswa untuk mengarahkan diskusi. Scaffolding merupakan bantuan yang diberikan secara bertahap untuk menyelesaikan masalah. Semakin tinggi proses scaffolding semakin tinggi hasil belajar siswa. Hasil yang senada juga diperoleholeh (Haniin et al., 2015; Rahmatiah et al., 2016). Hal ini sesuai dengan hasil penelitian. Penggunaan scaffolding pada siklus kedua dapat meningkatkan pemahaman konsep mahasiswa. Hal ini tercermin dari ratarata hasil belajar mahasiswa sebesar 79,4.

\section{SIMPULAN}

Berdasarkan analisis hasil penelitian, diperoleh kesimpulan bahwa penerapan metode pembelajaran diskusi dan scaffolding pada materi kuantisasi besaran fisis dapat meningkatkan hasil belajar mahasiswa pendidikan fisika. Berdasarkan hasil belajar mahasiswa pada siklus pertama dan siklus kadua, nilai rata-rata hasil belajar mahasiswa mengalami peningkatan. Pada akhir siklus kedua, nilai rata-rata hasil belajar sudah memenuhi indikator keberhasilan, yakni 79,4 .

\section{UCAPAN TERIMA KASIH}

Penulis mengucapkan terima kasih kepada Bapak Dr. Tatag Tuli Eko
Siswono, M.Pd. yang telah membimbing tugas Applied Approach (AA) dan Program Peningkatan Keterampilan Dasar Teknik Instruksional (PEKERTI). Melalui pengembangan AA dan PEKERTI tersebut, artikel ini dapat disusun. Selain itu, penulis juga mengucapkan terima kasih kepada Alfi Nurlailiyah, S.Pd. yang telah membantu mengedit artikel ini dan mahasiswa Pendidikan Fisika B 2012 sebagai subjek dari penelitian ini.

\section{DAFTAR PUSTAKA}

Anghileri, J. (2006). Scaffolding Practices that Enhance Mathematics Learning. Journal of Mathematics Teacher Education, 9(1), 33-52. https://doi.org/10.1007/s10857-0069005-9

Deta, U. A., -, S., \& Widha, S. (2013). Pengaruh Metode Inkuiri Terbimbing dan Proyek, Kreativitas, serta Keterampilan Proses Sains terhadap Prestasi Belajar Siswa. Jurnal Pendidikan Fisika Indonesia (Indonesian Journal of Physics Education), 9(1), 28-34. Retrieved from

http://journal.unnes.ac.id/nju/index.p $\mathrm{hp} / \mathrm{JPFI} /$ article/view/2577

Deta, U. A., \& Suprapto, N. (2012). Pembelajaran Fisika Model Diskusi Ditinjau dari Kecerdasan Intrapersonal Siswa. Jurnal Penelitian Fisika Dan Aplikasinya (JPFA), 2(1), 30-36.

Ding, L., Reay, N., Lee, A., \& Bao, L. (2011). Exploring the Role of conceptual Scaffolding in Solving Synthesis Problems. Physics Education Research, 7(2), 1-11. https://doi.org/10.1103/PhysRevSTP ER.7.020109

Dwikoranto. (2011). Aplikasi Metode Diskusi dalam Mengembangkan Kemampuan Kognitif, Afektif dan Sosial dalam Pembelajaran Sains. Jurnal Penelitian Fisika Dan Aplikasinya (JPFA), 1(2), 40-49. 
Haniin, K., Diantoro, M., \& H, S. K. (2015). Pengaruh Pembelajaran TPS dengan Scaffolding Konseptual terhadap Kemampuan Menyelesaikan Masalah Sintesis Fisika. Jurnal Pendidikan Sains, 3(3), 98-105.

Nadeak, N., Margiati, K. Y., \& Halidjah, S. (2013). Peningkatan Aktivitas Belajar Siswa Melalui Metode Diskusi dalam Pembelajaran IPS SD. Jurnal Pendidikan Dan Pembelajaran, 2(1).

Rahmatiah, R., H, S. K., \& Kusairi, S. (2016). Pengaruh Scaffolding Konseptual dalam Pembelajaran Group Investigation terhadap Prestasi Belajar Fisika Siswa SMA dengan Pengetahuan Awal Berbeda. Jurnal Pendidikan Fisika Dan Teknologi, II(2), 45-54.

Rohaniawati, D. (2016). Penerapan Pendekatan Pakem untuk Meningkatkan Keterampilan Berpikir Mahasiswa dalam Mata Kuliah Pengembangan Kepribadian Guru. Tadris: Jurnal Keguruan Dan Ilmu Tarbiyah, 1(2), 155-172.

Saregar, A. (2016). Pembelajaran Pengantar Fisika Kuantum dengan
Memanfaatkan Media PhET

Simulation dan LKM Melalui Pendekatan Saintifik: Dampak pada Minat dan Penguasaan Konsep Mahasiswa. Jurnal Ilmiah Pendidikan Fisika Al-Biruni, 5(1), 53-60.

https://doi.org/10.24042/jpifalbiruni. v5i1.105

Trianto. (2007). Model-Model Pembelajaran Inovatif Berorientasi Konstruktivisme. Jakarta: Prestasi Pustaka.

Wekke, I. S., \& Astuti, R. W. (2017). Kurikulum 2013 di Madrasah Ibtidaiyah : Implementasi di Wilayah Minoritas Muslim. Tadris: Jurnal Keguruan Dan Ilmu Tarbiyah, 2(1), 33-39.

https://doi.org/10.24042/tadris.v2i1.1 736

Yuliani, H. (2017). Pembelajaran Fisika Menggunakan Media Animasi Macromedia Flash-MX dan Gambar untuk Meningkatkan Pemahaman Konsep Mahasiswa. Jurnal Ilmiah Pendidikan Fisika Al-Biruni, 6(1), 13-21. https://doi.org/10.24042/jpifalbiruni. v6i1.596 